\title{
Changes in secretory status, cell height and percentage ciliation of epithelial lining of sheep fimbria oviduct during early pregnancy
}

\author{
M. K. Murray \\ Department of Anatomy and Cellular Biology. Tufts University, Schools of Veterinary Medicine, \\ Medicine and Dental Medicine, Boston, MA 0211, USA
}

\begin{abstract}
Studies have shown that the biosynthetic activity of the fimbria oviduct in the sheep changes during the first few weeks of pregnancy. The objective of the present study was to determine whether the secretory epithelial lining of the fimbria undergoes pregnancyassociated morphological alterations in a concordant manner. Oviducts obtained from ovariectomized, oestrous (day 0) and pregnant (day 1.5, 2, 3, 4, 6 and 16) ewes were analysed quantitatively and qualitatively using light and electron microscopy. The epithelium was low cuboidal in fimbria from ovariectomized sheep, significantly increased in height at day 1.5 of pregnancy, immediately decreased at day 2 , and underwent an additional slight reduction at day 6 and day 16 of pregnancy. Ciliated and nonciliated cells were present in the epithelium at all reproductive stages. The proportions of ciliated and nonciliated cells varied during pregnancy and ciliated cells were always the major cell type. Consistent with previous data, the secretory organelles of nonciliated epithelial cells obtained from ovariectomized ewes were poorly developed. Maturation of secretory organelles in nonciliated cells occurred at oestrus and was maintained until days 2-3 of pregnancy; regressive changes were then observed, characterized by atrophy of the Golgi apparatus and rough endoplasmic reticulum, and increases in heterochromatin and pronounced nuclear folds. Large, electron-dense lipid droplets were present throughout the cytoplasm of ciliated and nonciliated epithelial cells, beginning at day 1.5 of pregnancy and increasing at later stages of pregnancy. Apical protrusions and microvilli were observed at the luminal domains of nonciliated cells and were reduced in extent after day 3 of pregnancy. Cells were extruded from the epithelial lining at day 16 of pregnancy. These data show that the epithelial lining of the fimbria oviduct in the sheep undergoes distinct changes in cell height, percentage ciliation and secretory organelle development during the first few weeks of pregnancy.
\end{abstract}

\section{Introduction}

In vivo, the mammalian oviduct functions to retrieve ovulated oocytes and to provide a suitable environment for fertilization and ensuing embryonic development. Secretions of the oviduct contribute to the biochemical milieu in which these reproductive processes take place. Steroid-modulated and phase-specific glycoproteins have been described in the oviducts of several mammals (Verhage and Fazleabas, 1988; Verhage et al., 1988; Buhi et al., 1989; Boice et al., 1990; Murray, 1992, 1993; Malette and Bleau, 1993) and several workers have postulated that they enhance fertilization rates and the developmental competence of embryos (Gandolfi and Moor, 1987; Boatman et al., 1994; Hunter, 1994; King et al., 1994; Boatman and Magnoni, 1995). Molecular cloning has shown that these proteins represent a unique class of macromolecules which are highly conserved among mammalian species (Donnelly et al., 1991; Arias et al., 1994; Sendai, 1994, 1995; DeSouza and Murray, 1995; Malette et al., 1995; Suzuki et al., 1995).

Received 21 August 1995.
In sheep, an oestrogen-dependent oviduct-specific glycoprotein $\left(M_{\mathrm{r}} 90000-92000\right)$ is expressed, synthesized and released by the fimbria and ampulla oviduct in a temporalspecific fashion during the first few days of pregnancy at the time of ovulation, sperm-egg interactions and tubal transport of the embryo (Murray, 1993; DeSouza and Murray, 1995), where it associates with the fertilized ovum (Gandolfi et al., 1991). The $M_{r} 90$ 000-92 000 glycoprotein has been localized to lamellar secretory granules in the nonciliated epithelial cells of the ampulla, and its mRNA to the epithelial lining of both the fimbria and ampulla (Murray 1992; Murray and DeSouza, 1995).

The oestrogen-dependent $M_{\mathrm{r}} 90000-92000$ glycoprotein can be detected as a secretory product of ampulla explant cultures until day 16 of pregnancy, but only until day 3-4 in the fimbria (Murray, 1993), indicating that there is a biosynthetic gradient in sheep oviduct, perhaps owing to alterations in ovarian hormones that affect the secretory apparatus in a region-specific manner. In ewes, oestradiol is the major ovarian hormone until day 3 of pregnancy, when serum Downloaded from Bioscientifica.com at 04/26/2023 11:58:40AM 
progesterone concentrations are first detectable in the systemic circulation. Variations in the secretory status of the fimbria could be the result of modifications in the protein synthesizing machinery of secretory epithelial cells.

Therefore, to determine whether the epithelial lining of the fimbria undergo cytological alterations in the secretory apparatus during the first few days of pregnancy, oviducts were obtained from pregnant ewes and examined using light and electron microscopy. Specifically, using quantitative and qualitative structural analyses, the objective was to define the cytoplasmic, nuclear and cell surface changes that take place in the secretory epithelium of pregnant fimbria as the hormonal status transforms from an oestrogen-dominated to a progesterone-dominated state.

\section{Materials and Methods}

\section{Reagents}

Embedding and microscopy supplies were purchased from Polysciences, Inc. (Warrington, PA). Lutalyse was from UpJohn Vet Products, Inc. (Kalamazoo, MI). All other chemicals, of reagent grade or better, were purchased from Sigma Chemical Co. (St Louis, MO).

\section{Animals and collection of tissue}

Segments of fimbria used in this study were obtained from the same group of animals used to study the synthesis and release of an oestrogen-dependent oviduct glycoprotein from oviduct explant cultures and flushings during early pregnancy (Murray, 1993). Tissues were obtained from Florida native ewes following an i.m. injection of $10 \mathrm{mg}$ Lutalyse. Ewes were monitored twice a day for oestrous behaviour and mated with intact rams of known fertility on the first day of standing oestrus (day 0), and 12 and $24 \mathrm{~h}$ later. At the time of hysterectomy, oviducts were obtained from day 1.5, 2, 3, 4, 6 and 16 pregnant ewes, placed in Earle's modified Eagle's minimal essential medium and quickly trimmed of excess fat and mesentery. Pregnancy was confirmed by the presence of a functional corpus luteum and a fertilized ovum or conceptus. Fimbria oviduct tissue was obtained from three animals at each stage of pregnancy. For cytomorphometric study, oviduct tissue was also obtained from oestrous (day 0 ) animals $(n=3$ ), and from ewes that had been ovariectomized for 4-6 weeks $(n=3)$. We have shown that the epithelial lining of the fimbria oviduct from ovariectomized ewes is synthetically inactive and does not express, synthesize or release the oestrogendependent $M_{\mathrm{r}}$ 90000-92000 glycoprotein, whereas the oestrous fimbria contains well-developed secretory organelles and expresses, synthesizes and releases the $M_{\mathrm{r}} 90000-92000$ glycoprotein (Murray, 1993; DeSouza and Murray, 1995; Murray and DeSouza, 1995).

\section{Light and electron microscopy}

Portions of the fimbria were cut into $\approx 2 \mathrm{~mm}$ pieces, immersion-fixed in a Hepes-buffered solution containing $1 \%$

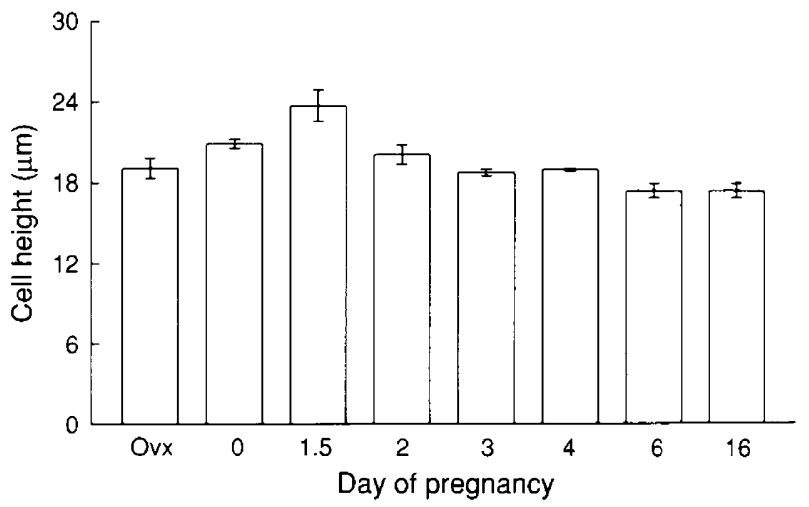

Fig. 1. Cell height of the fimbria epithelium of ewes. Values are means \pm SEM. The mean cell height of epithelial cells from oestrous (day 0 ) and day 1.5 of pregnancy was significantly $(P<0.05)$ higher when compared with ovariectomized (Ovx) animals. A significant reduction in cell height was observed at day 2 of pregnancy. Cell height continued to decline during pregnancy.

$(\mathrm{v} / \mathrm{v})$ glutaraldehyde and $3 \%(\mathrm{w} / \mathrm{v})$ paraformaldehyde for $2 \mathrm{~h}$ at room temperature and embedded in Araldite as described by Murray (1992). Thick $(1 \mu \mathrm{m})$ sections were cut on a Sorval MT-2B ultramicrotome, stained with toluidine blue and used for cytomorphometric analysis. The cell height was determined from three different tissue blocks per animal by measuring 50 cells per block using an ocular micrometer where cells were clearly sectioned through the longitudinal plane of the tissue. The cell height for a given animal was then calculated as the average of these determinations. The percentage of ciliated and nonciliated cells was made by randomly scanning 200 cells per block from three different blocks per animal. The percentage of a given cell type for each animal was calculated as the average of these measurements. For electron microscopy, silver sections were cut with a diamond knife, placed on copper grids, stained with lead citrate and uranyl acetate and examined using a Philips CM-10 electron microscope.

\section{Data analysis}

Values for cell height and per cent ciliation were expressed as the mean of three determinations \pm SEM. Differences between group means were determined by Mann-Whitney $U$ test and Kruskal-Wallis test. Values were considered to be significantly different when $P<0.05$.

\section{Results}

\section{Cytomorphometric study}

The epithelial lining of fimbria obtained from long-term ovariectomized ewes was low cuboidal and measured $\approx 19 \mu \mathrm{m}$ in height (Fig. 1). At oestrus, the epithelial cells increased in height to $\approx 21 \mu \mathrm{m}$ and underwent a further significant increase at day 1.5 of pregnancy to $\approx 24 \mu \mathrm{m}$. An immediate decline in cell height was observed at day 2 when cells measured $\approx 17 \mu \mathrm{m}$ tall at day 6 and day 16, a height below that measured in the fimbria obtained from ovariectomized ewes. 


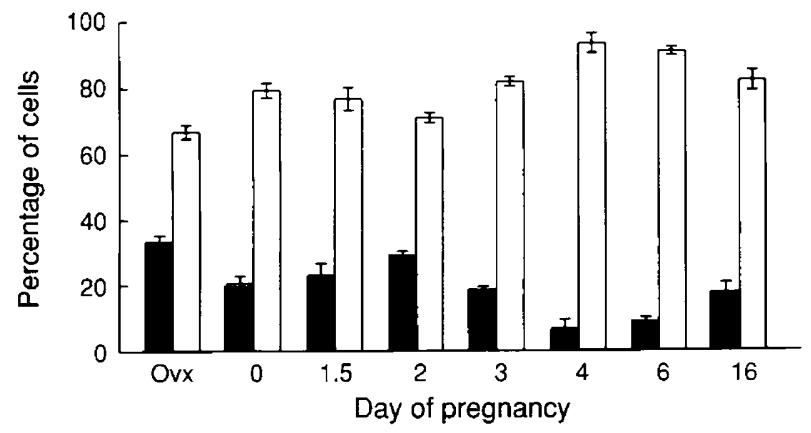

Fig. 2. Percentage of $(\square)$ ciliated and ( $\square$ ) nonciliated cells in fimbria oviducts obtained from ovariectomized $(\mathrm{Ovx})$, oestrous (day 0$)$ and pregnant (day 1.5, 2, 3, 4, 6 and 16) ewes. Values are means \pm SEM. The relative percentage of ciliated and nonciliated cells varied depending upon the reproductive status.

Ciliated and nonciliated cells were present in the fimbria epithelium obtained from ovariectomized, oestrous and pregnant ewes and the relative percentage of each cell type varied depending upon the reproductive stage (Fig. 2). At all stages examined, ciliated cells were the predominant cell type. An increase in one cell type led to a proportionate decrease in the other cell type. The percentage of ciliated cells showed a significant rise to $\approx 79 \%$ of the total epithelial cell population at oestrus, compared with $\approx 67 \%$ in ovariectomized animals. A significant reduction in the percentage of ciliated cells was observed at day $2(\approx 71 \%)$, which then increased at day 3 to $\approx 82 \%$ and reached a maximum at day 4 representing $\approx 94 \%$ of the total number of epithelial cells. The percentage of ciliated cells was reduced to $\approx 91 \%$ at day 6 and about $\approx 82 \%$ at day 16 of pregnancy. Variations in the nonciliated cells mirrored those observed for ciliated cells. The percentage of nonciliated cells was highest in ovariectomized epithelium $(\approx 33 \%)$, declined significantly at oestrus $(\approx 21 \%)$, increased at day 2 $(\approx 29 \%)$, underwent a reduction at day $3(\approx 18 \%)$ and reached a minimum at day $4(\approx 6 \%)$. By day 6 of pregnancy, nonciliated cells were $\approx 9 \%$ of the total epithelial cell population and subsequently doubled to $\approx 18 \%$ of the epithelial cells by day 16 of pregnancy.

Variations in the quantitative parameters of cell height and type were manifested as changes in the fine structure of epithelial cell cytology.

\section{Light and electron microscopy}

The light microscopic and ultrastructural details of the fimbria epithelium obtained from ovariectomized and oestrous ewes were described by Murray and DeSouza (1995). The epithelial lining of the ovariectomized fimbria are characterized by low cuboidal cells and poorly developed secretory organelles. In contrast, the tall columnar epithelial cells of the oestrous fimbria are distinguished by a mature secretory apparatus and apical luminal projections in nonciliated cells. These observations were confirmed in the present study.

The fimbria epithelial cells at day 1.5 of pregnancy contained nuclei composed primarily of euchromatin and distinct nucleoli (Figs 3a,4). Light microscopy showed that the cytoplasm of cells stained with various intensities (Fig. 3a). Epithelial cells were slender in appearance, had a basophilic staining cytoplasm and elongated nuclei located at various levels. The abundance of densely packed ciliated cells obscured the presence of nonciliated cells in light micrographs. Ultrastructurally, the apical plasma membrane of nonciliated or secretory cells contained long, evenly spaced, finger-like microvilli projecting into the oviduct lumen (Fig. 4). Lipid droplets and elongated mitochondria were found in the supranuclear domains of secretory and ciliated cells (Fig. 4). In nonciliated cells, a few granules were scattered throughout the cytoplasm (Fig. 4) and well-developed Golgi apparatus consisted of multiple stacks of flattened saccules (Fig. 5). The maturing of the Golgi was associated with vesicles of various sizes (Fig. 5). The cytoplasm of nonciliated cells was filled with profiles of dilated endoplasmic reticulum (Fig. 5).

Similar to day 1.5 of pregnancy, the epithelial lining of the fimbria at day 2 was characterized by a single layer of pseudostratified cells (Fig. 3b). Nuclei of differing densities were observed at all levels in the epithelium (Fig. 3b). A few oval cells with little cytoplasm and darkly staining nuclei were seen near the luminal margins (Fig. $3 \mathrm{~b}$ ). The apices of secretory or nonciliated cells protruded into the oviduct lumen for variable distances (Fig. 6). In some secretory cells, the apical tips extended well beyond the most distal surface of adjacent ciliated cells and were covered by long microvilli (Fig. 6). In contrast, other secretory cells showed only a moderate extension beyond the apical plasma membrane of ciliated cells and contained few microvilli (Fig. 6). On occasion, vacuoles with a delimiting membrane were observed in the apical blebs of nonciliated cells (Fig. 6). Ultrastructurally, the cytoplasm of ciliated and nonciliated cells was very dense and included multiple circular profiles of smooth endoplasmic reticulum and dilated rough endoplasmic reticulum (Figs 6 and 7). Free ribosomes were also scattered throughout the cytoplasm (Fig. 7). Oval and elongated mitochondria were present characteristically in the apical cytoplasm of ciliated and nonciliated cells (Fig. 6) and intimately associated with cisternae of the endoplasmic reticulum (Fig. 7). In addition, a few nonciliated cells had a solitary cilium extending from a single pair of centrioles to the apical plasma membrane (Fig. 6).

The fine structure of epithelial cells changed slightly at day 3 of pregnancy (Fig. 3c). Nuclear folds and heterochromatin at the peripheral margins of the nuclear membrane were more prominent in both ciliated and nonciliated cells at this stage of pregnancy (Fig. 8a). Large, electron-dense lipid droplets were present in the cytoplasm of epithelial cells (Fig. 8). The lateral plasma membranes of epithelial cells showed interdigitation (Fig. 8b). The Golgi apparatus was flattened and numerous circular membrane profiles were prevalent in the supranuclear regions of nonciliated cells (Fig. 8b). Similar to day 2 of pregnancy, the apical cytoplasm of secretory cells was crowded with organelles and formed blebs that protruded by various degrees into the lumen. A few secretory granules were visible in some of the nonciliated cells (Fig. 8b). These membranebound granules were always located near the apical plasma membrane and the content varied in electron density (Fig. $8 \mathrm{~b}$. insert). Release of the contents of granules by either merocrine or apocrine secretion was never observed at any stage of pregnancy examined. Mitochondria, in close association with sparsely distributed cisternae and vesicles of the rough 

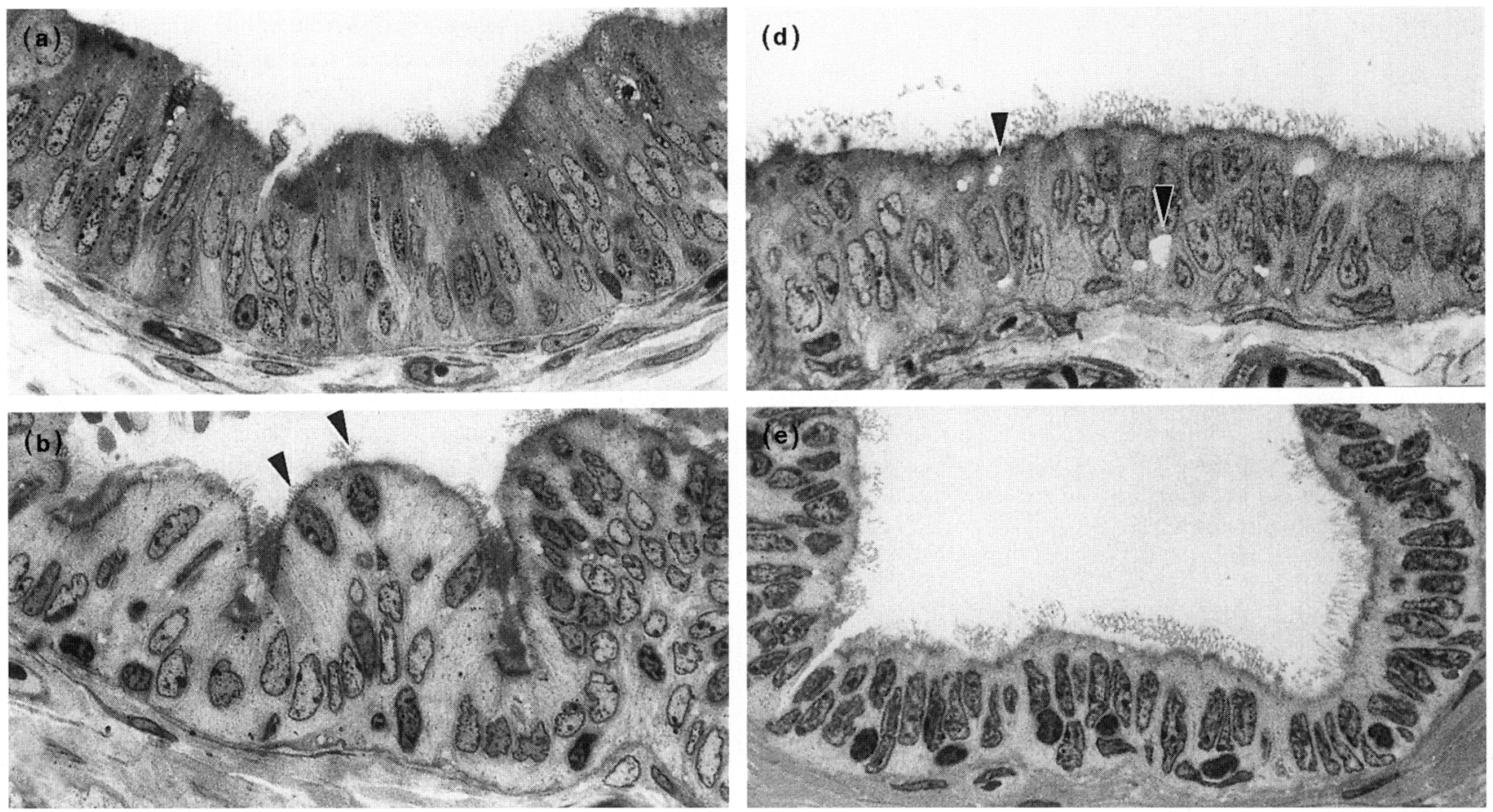

\section{(c)}
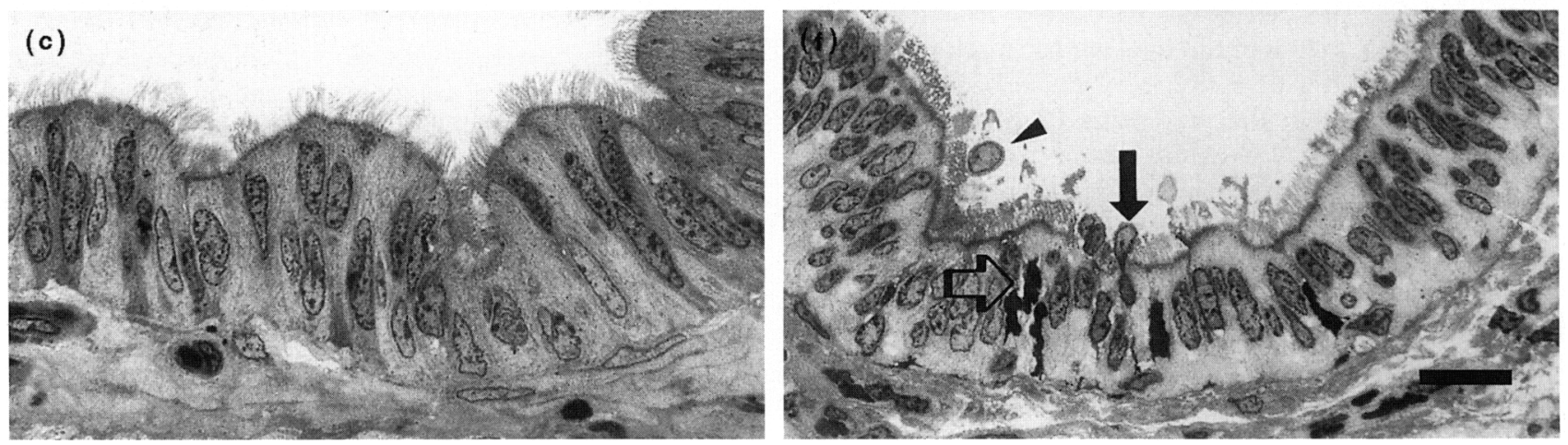

Fig. 3. Light micrographs of the epithelium of the fimbria oviduct obtained from pregnant ewes: (a) day I.5: epithelium was tall columnar; (b) day 2: cells with dense nuclei were seen at the luminal border of the epithelium (arrowheads); (c) day 3: epithelium remained pseudostratified; (d) day 4: vacuoles were seen in the cytoplasm (arrowheads); (e) day 6: epithelium was atrophied; ( $\mathrm{f}$ ) day 16, vacuoles surrounding darkly stained material (open arrow) were seen in the cytoplasm. Cells were extruded from the epithelium (arrow) and present in the lumen (arrowhead). Scale bar represents $3.5 \mu \mathrm{m}$.

endoplasmic reticulum, were also visible in the apical domains of epithelial cells (Fig. 8b). Although microvilli were present at the apical plasma membrane of nonciliated cells, their arrangement appeared less orderly and they were shorter than earlier in pregnancy (compare Figs 4 and 6 with Fig. 8b).

Regression of the fimbria epithelium was obvious at day 4 of pregnancy (Fig. 3d). The nuclei were composed primarily of heterochromatin. A distinguishing feature of both ciliated and nonciliated cells was the presence of abundant, large, electrondense lipid droplets that were frequently associated with poorly developed rough endoplasmic reticulum at their edges (Fig. 9). Under the light microscope, vacuoles were seen in the supra- and infra-nuclear domains of epithelial cells, perhaps representing lipid droplets extracted during tissue preparation (Fig. 3d). Ultrastructurally, the lipid droplets were irregular in shape, more electron dense at their peripheral margins and occurred throughout the cytoplasm (Fig. 9a,c). The apical cytoplasm of nonciliated cells was characterized by circular membranous profiles and mitochondria (Fig. 9b). Membranebound cytoplasmic structures, possibly multivesicular bodies, were present in the apical cytoplasm (Fig. 9c). Secretory blebs were reduced and microvilli shorter in nonciliated cells when compared with those at day 3 of pregnancy (compare Fig. $8 \mathrm{~b}$ with Fig. 9b). Secretory granules were not present in the cytoplasm of nonciliated cells. Mitochondria and scant condensed vesicular profiles of endoplasmic reticulum were observed in the cytoplasm of nonciliated cells (Fig. 9b).

The luminal epithelial surface was more even by day 6 of pregnancy (Fig. 3e). Deep folds and abundant heterochromatin continued to characterize the nuclei of ciliated and nonciliated cells. Differences in electron densities of ciliated and nonciliated cells were readily apparent. The staining of nonciliated cells was paler and the ciliated cells were darker (data not shown). Similarly to day 4 of pregnancy, large 


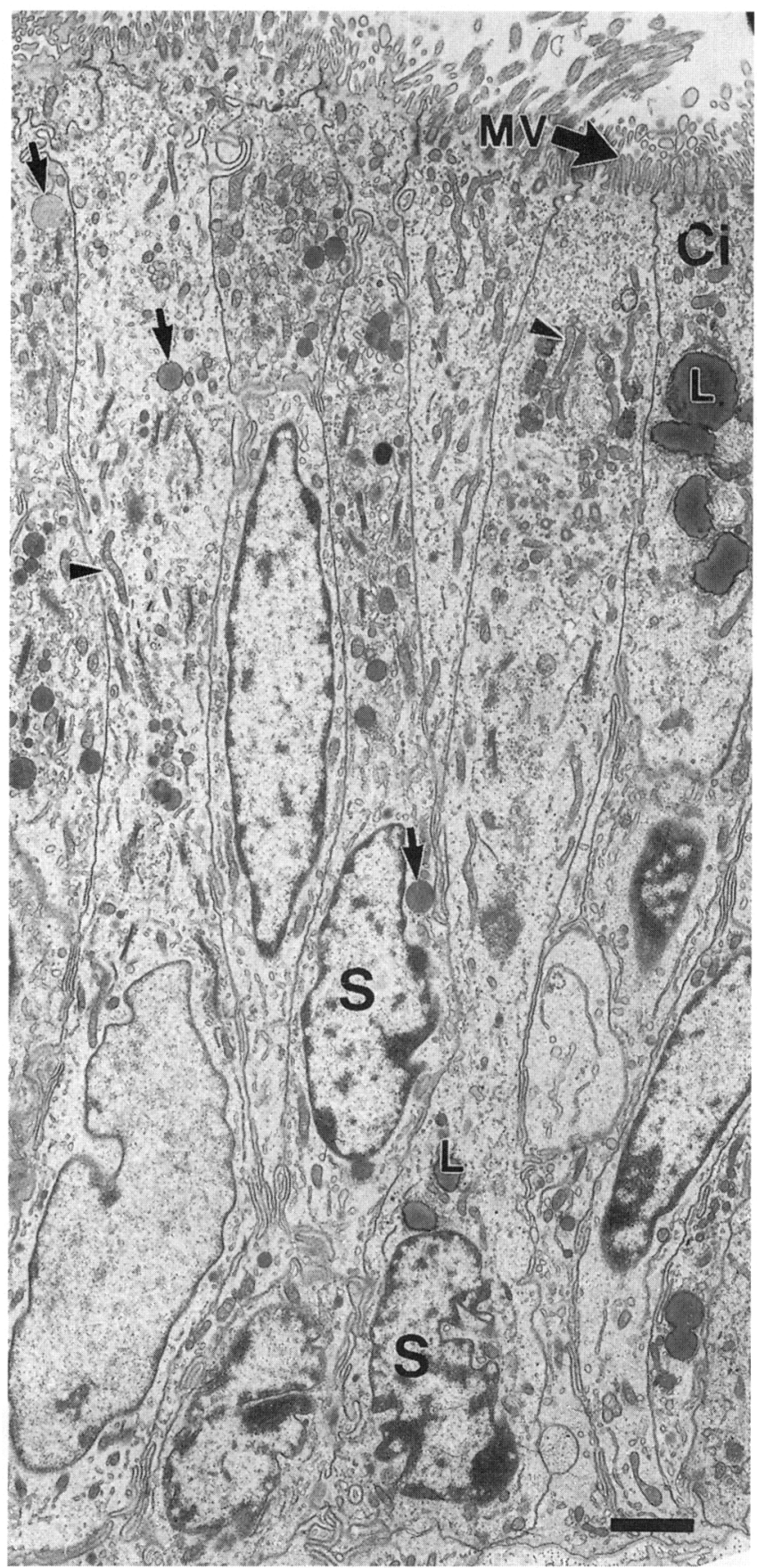

Fig. 4. Ciliated $(\mathrm{Ci})$ and nonciliated or secretory $(\mathrm{S})$ cells of a day 1.5 pregnant ewe. Extensive microvilli were present at the apical plasma membrane of nonciliated cells (arrow, MV). Note the presence of large lipid droplets (L). Elongated mitochondria (arrowheads) were present throughout the cytoplasm. Granules were scattered in the supranuclear region of secretory cells (arrows). Scale bar represents $2 \mu \mathrm{m}$.

pleomorphic, electron-dense lipid droplets were scattered throughout the cytoplasm of epithelial cells. Components of the secretory apparatus, including the Golgi and rough endoplasmic reticulum, were poorly developed and sparse.

Atrophy and dedifferentiation of the fimbria epithelium continued at day 16 of pregnancy (Figs $3 \mathrm{f}, 10$ and 11). The nuclei of many cells were located at the luminal margins of

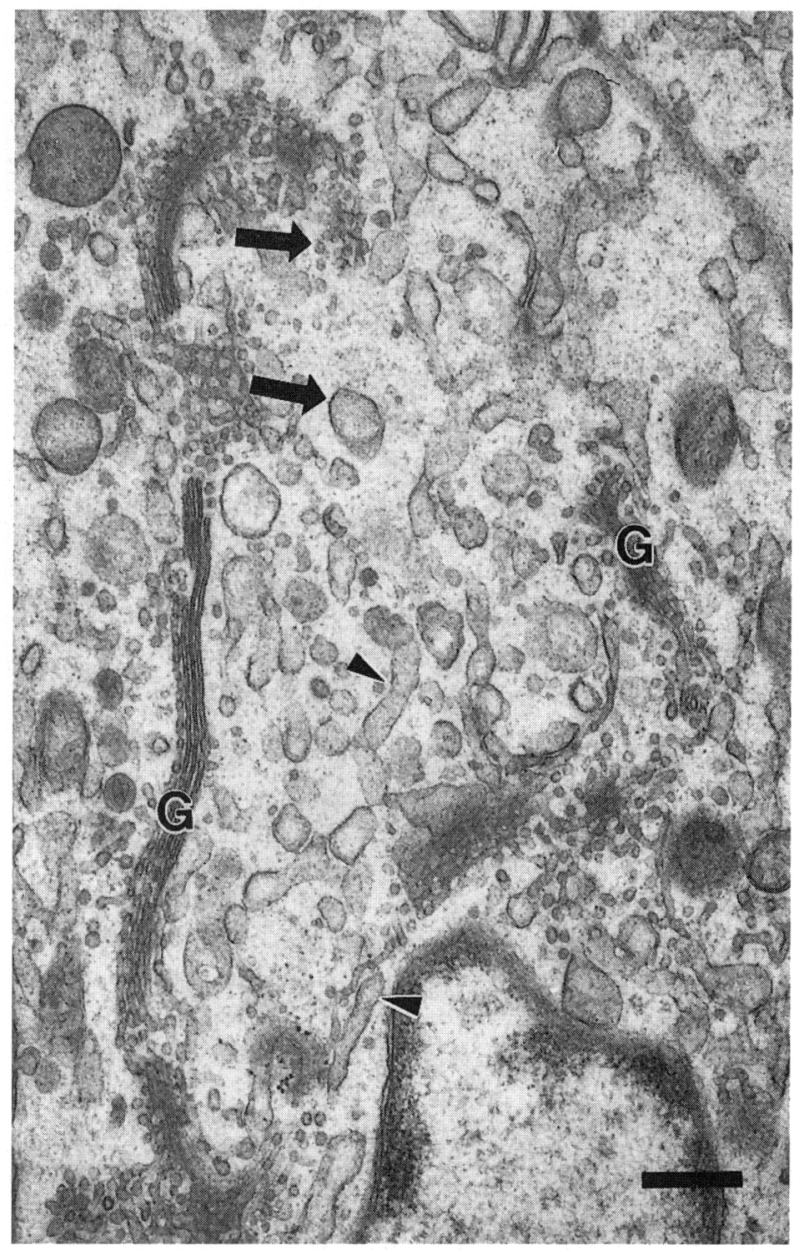

Fig. 5. Portion of the supranuclear cytoplasm of a secretory cell of a day 1.5 pregnant ewe. Multiple, well developed Golgi apparatus (G) were observed. Circular vesicles (arrows) and endoplasmic reticulum (arrowheads) were present. Scale bar represents $0.4 \mu \mathrm{m}$.

cells and contained predominantly heterochromatin (Figs $3 \mathrm{f}$ and 10). Cells were extruded from the epithelial lining into the oviduct lumen (Figs $3 \mathrm{f}$ and 10a). These small cells had sparse, degenerating cytoplasm and dense nuclei. The apical protrusions of nonciliated cells were low with a few cells extending beyond the tips of ciliated cells. The supranuclear Golgi complex was smail and consisted of compressed saccules, and circular profiles of membranes and numerous polyribosomes were present in the cytoplasm of secretory cells (Fig. 11). Secretory granules were absent in nonciliated cells. Mitochondria were a major cellular organelle of both ciliated and nonciliated cells, particularly in the apical cytoplasm (Fig. 10b,c). Lipid droplets were plentiful in ciliated and nonciliated cells. In light micrographs, they appeared as darkly staining, irregularly shaped material surrounding cytoplasmic vacuoles (Fig. 3f). Ultrastructurally, lipid droplets were multiplex structures, asymmetrically associated with a fine filamentous matrix (Fig. 10b,c). The perimeter of the lipid component of these structures was more electron dense than was the core and often in close spatial positioning with flattened rough endoplasmic reticulum (Fig. 10b). Lipid droplets were also observed in the oviduct lumen (Fig. 10). 

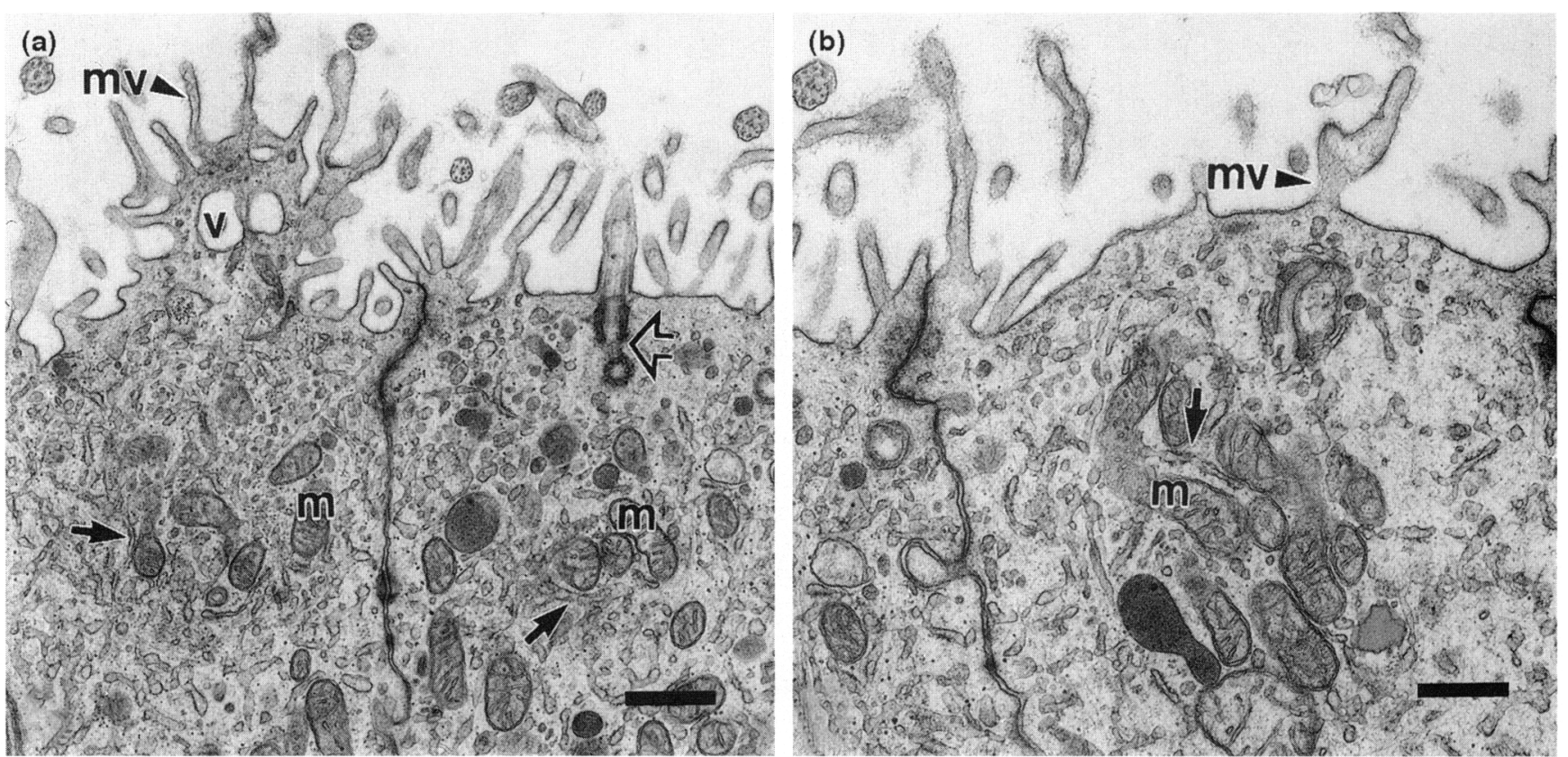

Fig. 6. Epithelial lining of a day 2 pregnant ewe. Oval and elongated mitochondria $(m)$ were present, frequently associated closely with rough endoplasmic reticulum (arrows). Numerous circular membranous profiles crowded the cytoplasm. (a) Apical cytoplasmic blebs that extended beyond the tips of ciliated cells contained long microvilli (arrowhead, mv) and vacuoles (v). Note the presence of a solitary cilium extending from a pair of centrioles (open arrow). Scale bar represents $0.7 \mu \mathrm{m}$. (b) The apical cytoplasm of secretory cells that did not extend beyond the ciliated cells contained a few microvillous projections (arrowhead, mv). Scale bar represents $0.5 \mu \mathrm{m}$.

\section{Discussion}

In the present study use of light and electron microscopy showed that the epithelial lining of the fimbria in the sheep underwent distinctive changes in cell height, percentage ciliation and secretory organelle organization during the first few weeks of pregnancy. In ewes, oestradiol concentration is high at oestrus and declines $24 \mathrm{~h}$ later, after ovulation. Serum progesterone concentrations are first detectable in the systemic circulation at day 3 of pregnancy as the fertilized ovum leaves the oviduct and enters the uterus (Bazer and First, 1983). Therefore, in pregnant ewes maximal epithelial cell height and secretory organelle maturation occurred when oestradiol was the major ovarian hormone, specifically when oocyte retrieval and fertilization were taking place in the oviduct. These data underscore a close link between a mature epithelial cell cytoarchitecture and the physiological contribution of the oviduct to the reproductive process.

The epithelial lining of the sheep ampulla oviduct undergoes marked changes in secretory organelle maturation during early pregnancy (Murray, 1995). The nonciliated cells of the ampulla contain numerous lamellar secretory granules compared with the occasional number observed in the fimbria. The alterations observed in the fimbria were less striking, yet undoubtedly varied depending upon the stage of pregnancy. Maximal cell height and secretory cell and organelle maturation occurred at a time corresponding to oocyte retrieval: a physiological process attributed, in part, to the fimbria. Morphological variations in steroid responsiveness among the regions of the oviduct have been reported in primates (Odor et al., 1983; Verhage et al., 1990; Brenner and Slayden, 1994) and cows (Eriksen ef al., 1994). In monkeys, the fimbria is most sensitive

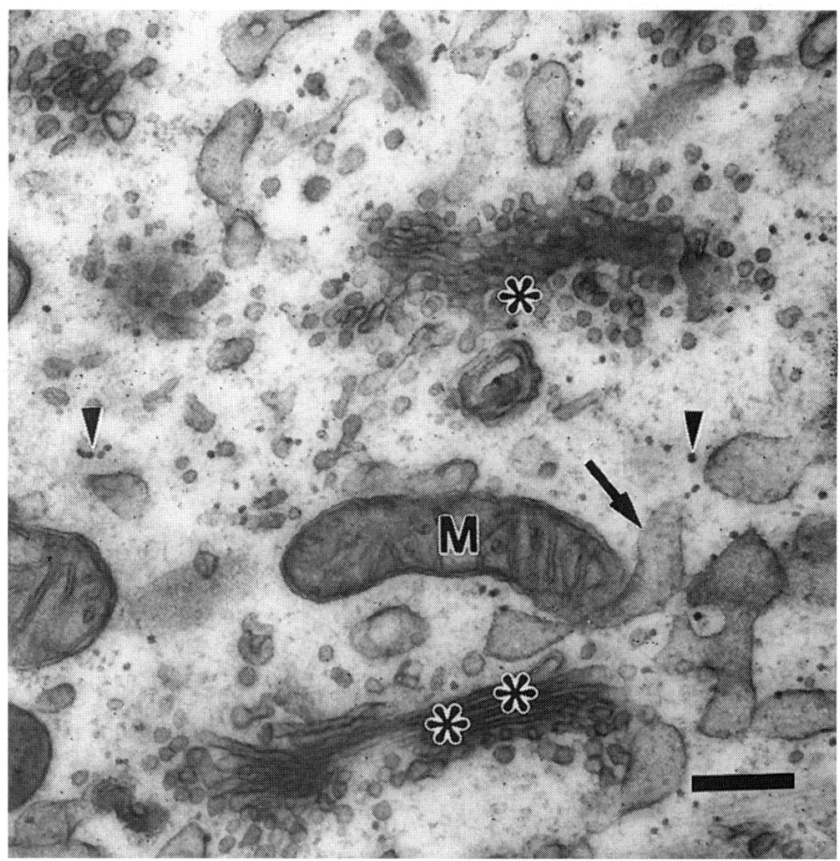

Fig. 7. Portion of secretory cell of a day 2 pregnant ewe. The Golgi apparatus was flattened (asterisks). Mitochondria (M) were in close association with dilated rough endoplasmic reticulum (arrow), and scattered free ribosomes (arrowheads) were observed. Scale bar represents $0.24 \mu \mathrm{m}$.

to changes in concentrations of ovarian hormones, the ampulla less and the isthmus least (Brenner and Slayden, 1994). A steroid-modulated biosynthetic gradient occurs in the sheep 

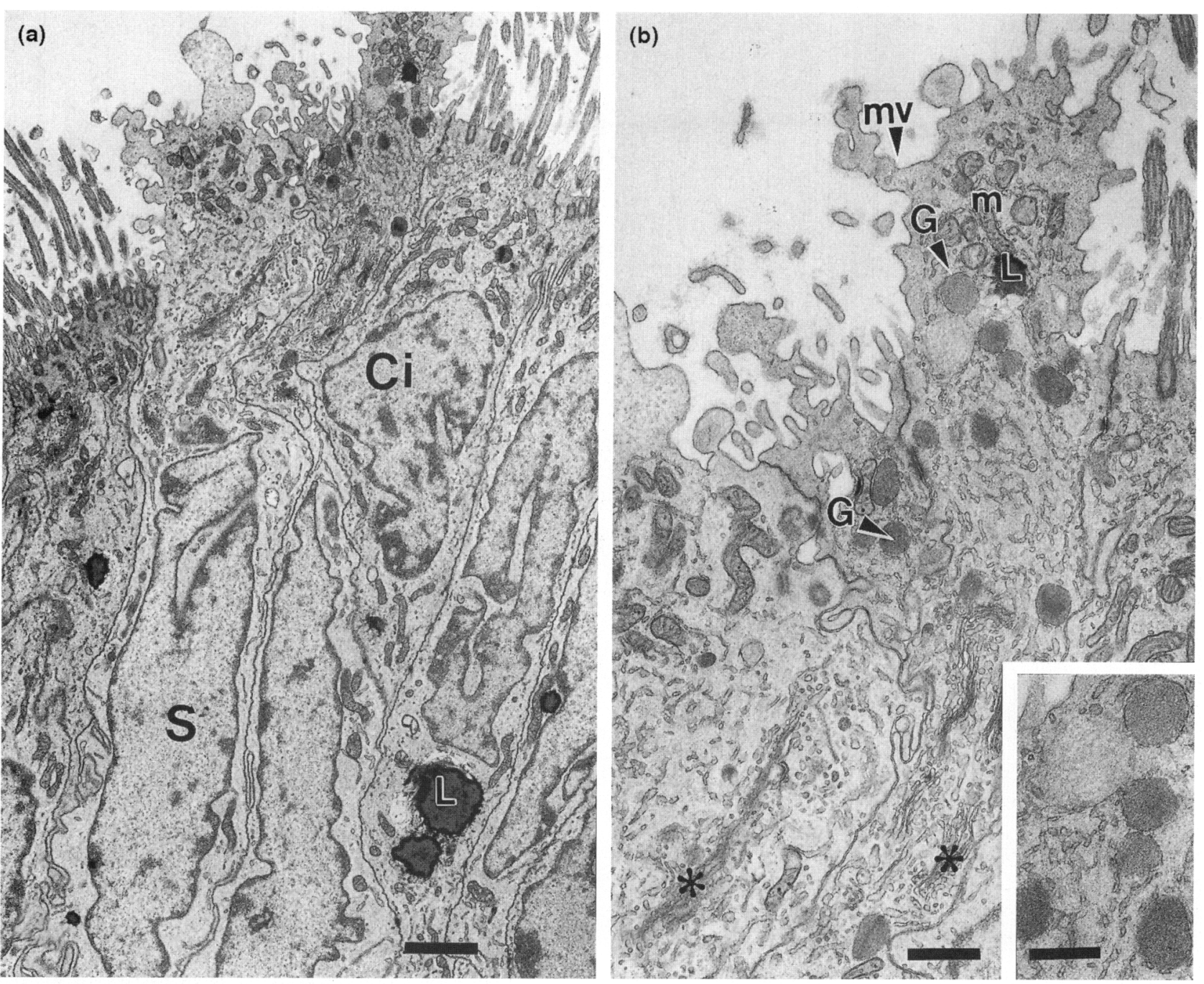

Fig. 8. Epithelial lining of a day 3 pregnant ewe. (a) Ciliated $(\mathrm{Ci})$ and nonciliated or secretory (S) cells were present. The nuclear membrane was folded. Electron-dense lipid droplets (L) were seen in the cytoplasm. Scale bar represents $2 \mu \mathrm{m}$. (b) Membrane-bound granules (arrowhead, G), which appeared to be lamellar in substructure, were present in the apical cytoplasm and irregular microvilli (arrowheads, mv) protruded from nonciliated cells. The Golgi apparatus (asterisks) consisted of multiple stacks of flattened saccules. Mitochondria ( $\mathrm{m}$ ) and numerous circular membranous profiles were present in the apical cytoplasm of ciliated and nonciliated cells. Scale bar represents $0.8 \mu \mathrm{m}$. Insert: secretory granules. Scale bar represents $0.45 \mu \mathrm{m}$.

oviduct, whereby the expression, synthesis and release of an oestrogen-dependent $M_{\mathrm{r}} 90000-92000$ glycoprotein varies in the fimbria and ampulla (Murray, 1993; DeSouza and Murray, 1995). The present data indicate that, in addition to in vivo and in vitro protein synthesizing capabilities (Murray, 1993; DeSouza and Murray, 1995), the ampulla and fimbria vary in epithelial cytology during early pregnancy, a phenomenon that may account for the reported biosynthetic differences.

Although the $M_{\mathrm{r}} 90000-92000$ oestrogen-dependent glycoprotein can be detected in fluorographs and western blots as a secretory product of the pregnant fimbria and ampulla (Murray, 1993), light and electron microscope immunocytochemistry have been able to localize the protein only to lamellar secretory granules in nonciliated epithelial cells of the ampulla (Murray, 1992; Murray and DeSouza, 1995). In situ hybridization strategies using nonradioactive riboprobes specific for the mRNA encoding the $M_{\mathrm{r}} 90000-92000$ oviduct protein have localized transcripts to the epithelial lining of both the ampulla and fimbria (Murray and DeSouza, 1995). Electron microscopy has now shown that few, if any, lamellar secretory granules are found in the fimbria, which could explain why the $M_{\mathrm{r}} 90000-92000$ protein was not detected in tissue sections of the fimbria. It is plausible that the fimbrial source of the oestrogen-dependent protein is not sequestered in large amounts as secretory granules, but rather exists as cytoplasmic stores translated from cellular accumulations of mRNA upon demand as ovarian hormone concentrations fluctuate.

Exocytosis of lamellar secretory granules has been reported in oviducts of baboons (Verhage et al., 1990), cats (Bariether and Verhage, 1981), pig-tailed monkeys (Odor et al, 1983) and cows (Eriksen et al., 1994), whereas Ferenczy and Richart (1974) suggested that apocrine secretion releases granular contents in humans. In the present study, there was no morphological 

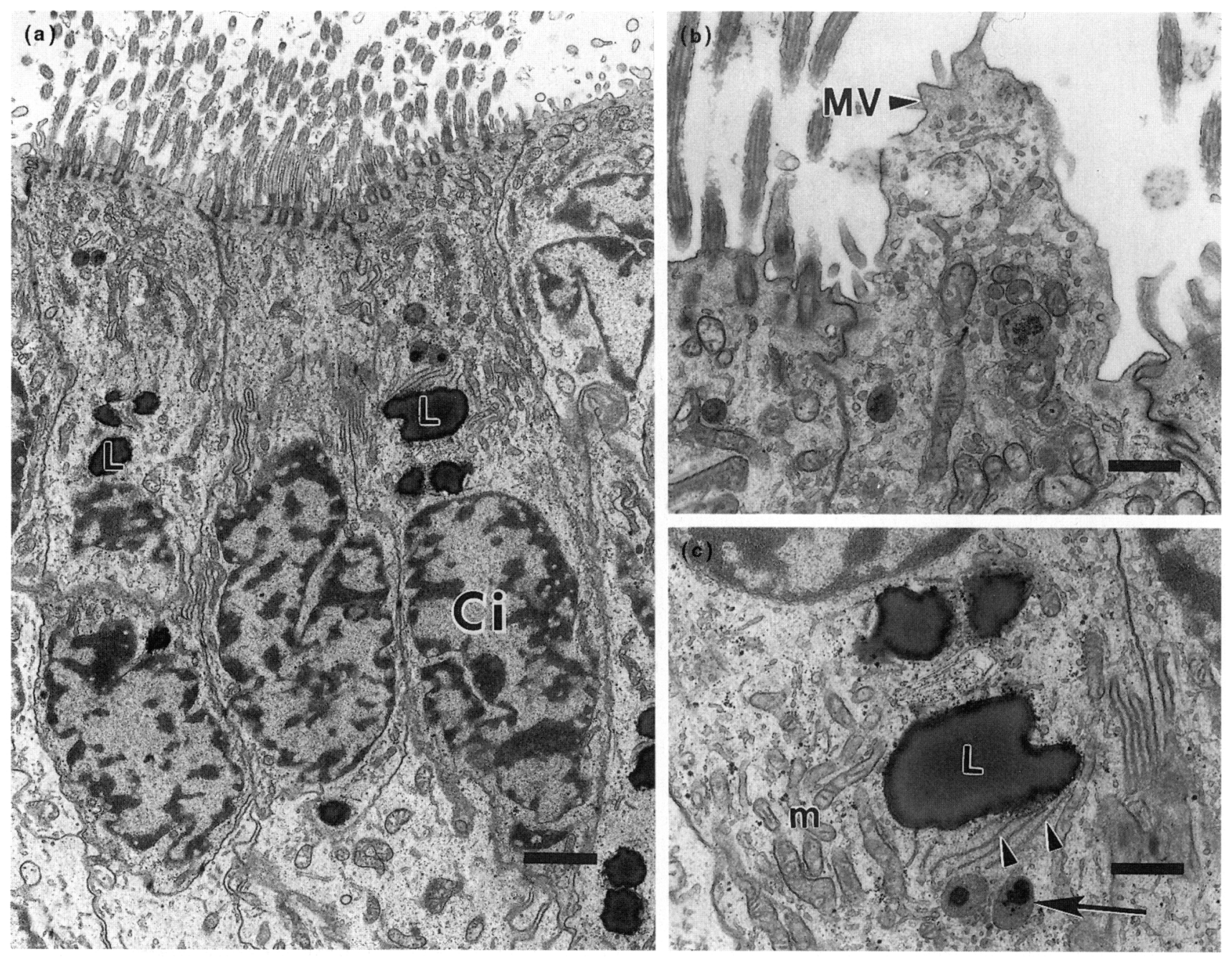

Fig. 9. Epithelial lining of a day 4 pregnant ewe. (a) Abundant heterochromatin and nuclear folds were observed. Large lipid droplets (L) were present in the cytoplasm of ciliated $(\mathrm{Ci})$ and nonciliated cells. Scale bar represents $0.2 \mu \mathrm{m}$. (b) Microvilli were reduced (arrowheads, mv). Scale bar represents $0.7 \mu \mathrm{m}$. (c) Mitochondria $(\mathrm{m}$ ) and poorly developed rough endoplasmic reticulum (arrowheads) were found in close proximity to lipid droplets. Membrane bound vesicles, possibly multivesicular bodies, were present in the apical cytoplasm (arrow). Scale bar represents $0.6 \mu \mathrm{m}$.

evidence of either merocrine or apocrine modes of secretion in the fimbria. Since electron microscopy represents a static analysis, it is possible that secretion mechanisms were not adequately documented. In the fimbria, the apices of nonciliated cells were irregular and protruded by various degrees into the oviduct lumen, perhaps suggesting an apocrine form of release. In rhesus monkeys, such images were construed as indicative of apocrine secretion (Pathak et al., 1979). Serial thin sections would need to be viewed to confirm whether constriction of a major portion of the apices of nonciliated cells ultimately resulted in the cytoplasm being pinched off into the lumen.

Histochemical staining and biochemical analysis of tissue homogenates in cow oviduct indicated the presence of several classes of lipid that vary in composition and morphology, depending upon the stage of the oestrous cycle and region of the oviduct (Henault and Killian, 1993a,b). Ultrastructurally, categories of lipid droplet were discerned that ranged from membrane-enclosed structures to myelin-like masses in epithelial cells (Henault and Killian, 1993b). In sheep, lipid inclusions were present in ciliated and nonciliated cells of the fimbria, were not surrounded by a membrane and increased at later stages of pregnancy associated with rising serum progesterone concentrations. It has been suggested that epithelium-derived lipids may influence fertilization or embryonic development by altering plasma membrane dynamics or by providing energy sources to the gametes (Henault and Killian 1993b). The importance of an increase in cytoplasmic lipid bodies in the fimbria at later stages of pregnancy, significantly after fertilization and tubal transport of the embryo has taken place, is unclear. Schmitz and Muller (1991) reported lamellar lipid droplets in cells in which lipid metabolism has been disturbed. It is possible that a distinguishing feature of fimbria epithelial regression includes, in addition to cellular and secretory organelle atrophy, alterations in lipid processing pathways, which are manifested as cytoplasmic accumulations.

Programmed cell death or apoptosis and shedding of cells from the epithelial lining have been proposed as mechanisms 
(a)
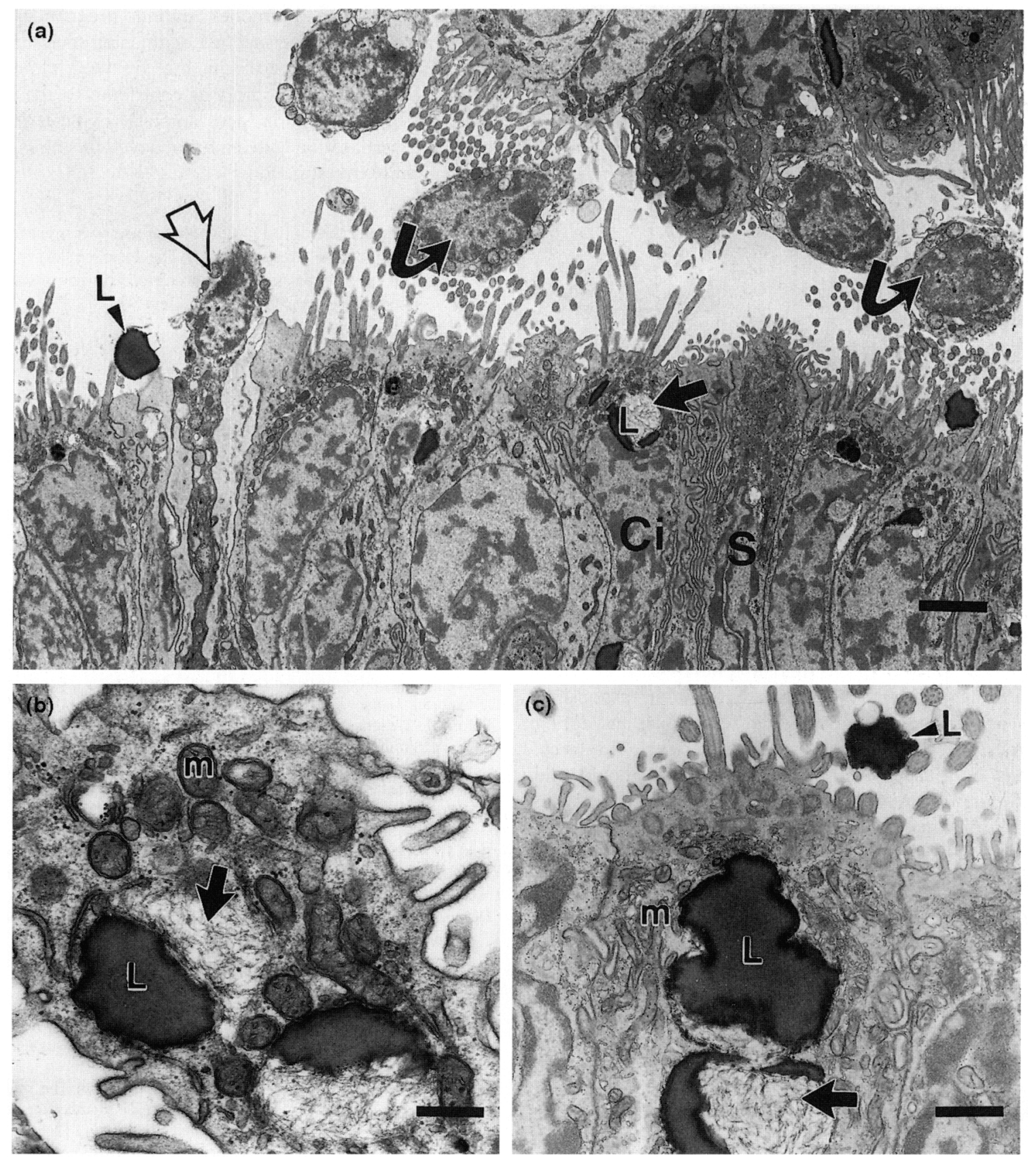

Fig. 10. Ciliated (Ci) and nonciliated or secretory $(\mathrm{S})$ cells of a day 16 pregnant ewe. Lipid droplets $(\mathrm{L})$ were irregularly shaped and appeared to be merged with filamentous material (arrow) in both ciliated and nonciliated cells. Oval and elongated mitochondria (m) were present in the apical cytoplasm of cells. Lipid material (arrowhead, L) and cells with little cytoplasm (curved arrows) were seen in the lumen. A cell in the process of being extruded from the epithelium (open arrow) was observed. (a) Scale bar represents $2 \mu \mathrm{m}$. (b) Apex of nonciliated cell. Scale bar represents $0.4 \mu \mathrm{m}$. (c) Apex of ciliated cell. Scale bar represents $0.8 \mu \mathrm{m}$.

for cellular turnover in the oviducts of several mammals (Odor ef al., 1980; Bariether and Verhage, 1981; Sawyer et al., 1984; Verhage et al., 1990; Brenner and Slayden, 1994). In cats (Bariether and Verhage, 1981) and baboons (Verhage ot al., 1990), apoptotic figures, characterized by cytoplasmic and nuclear fragmentation, increased when progesterone was administered to oestradiol-treated ovariectomized animals, suggesting strongly that ovarian hormones modulate this form of cellular demise. In the sheep ampulla oviduct, no cytological signs of apoptosis could be documented with light and electron microscopy; however, extrusion of epithelial cells into the oviduct lumen was observed at day 16 of pregnancy (Murray, 1995). Similarly, in the present study, no evidence for apoptosis was seen, but the presence of shrunken epithelial cells with dense nuclei in the lumen at day 16 suggests that cell death occurred in an analogous temporal and mechanistic manner 


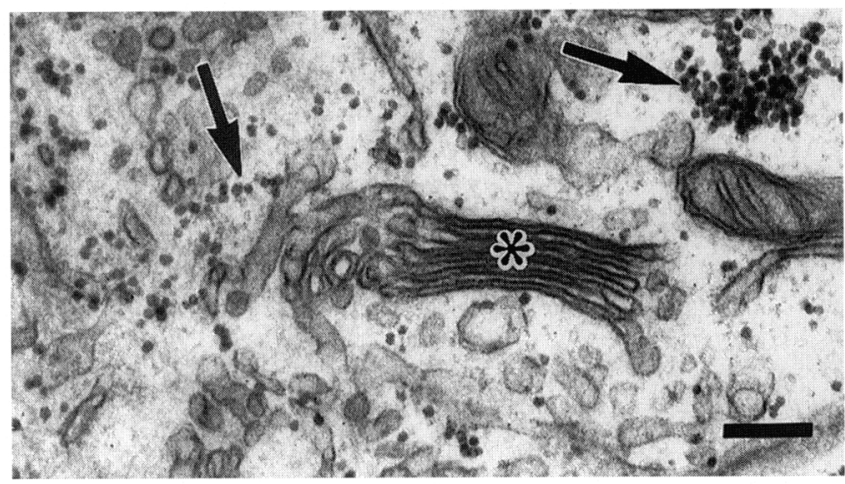

Fig. 11. Portion of a secretory cell of a day 16 pregnant ewe. The Golgi (asterisk) was poorly developed and numerous polyribosomes were present (arrows). Scale bar represents $0.18 \mu \mathrm{m}$.

in the fimbria. It is possible that apoptosis occurs after day 16 of pregnancy after chronic exposure to serum nidatory progesterone.

Several studies have shown that mature ciliated cells are necessary for ovum transport (Eddy et al., 1978; McComb et al., 1980). In primates (Verhage et al., 1990; Brenner and Slayden, 1994) and carnivores (Bariether and Verhage, 1981), ciliogenesis is dependent upon oestradiol. In these species, the oviduct of the ovariectomized animal contains a single, nonciliated epithelial cell type. New cilia are formed in response to oestradiol administration to ovariectomized animals and during the oestrous phase or follicular phase of the cycle. In sheep, ciliated and nonciliated cells are present in the ampulla and fimbria oviduct obtained from ovariectomized, oestrous, pregnant and steroid-treated animals (Murray, 1992, 1995; Murray and DeSouza, 1995). The increase in the percentage of ciliated and parallel reduction in nonciliated cells observed at oestrus, a time of high oestradiol concentration in the sheep fimbria, suggests that a portion of the epithelial cell population gives rise to ciliated cells in a steroid-dependent fashion. Moreover, the rise in the percentage of nonciliated cells and comparable decrease in ciliated cells at day 6 and day 16 of pregnancy, when serum progesterone concentrations are high, supports the notion of a hormonal modulation of ciliogenesis, even though both cell types persist in the absence of hormonal influences. A fully developed and maximally ciliated fimbria epithelial lining is likely to be important in directing and transporting ovulated oocytes into the lumen of the oviduct.

In summary, the present study showed that the epithelial lining of the fimbria oviduct in sheep underwent structural alterations during early pregnancy, which varied in degree from those reported for the ampulla (Murray, 1995). The most notable differences included the presence of increasing amounts of lipid droplets with advancing stage of pregnancy, only a few secretory granules in nonciliated cells, more subtle changes in secretory organelle characteristics, shifts in the percentage of ciliated cells, and the lack of evidence for a secretion mechanism in the fimbria. The data presented here confirm that, in addition to variations in the expression, synthesis and release of an oviduct-specific glycoprotein (Murray, 1993; DeSouza and Murray, 1995), the sheep oviduct undergoes morphological changes during early pregnancy. The ability of epithelial cells in regions of the oviduct to respond in different ways to circulating ovarian hormones during pregnancy may be important in mediating defined segmental specializations as reproductive events occur in the oviduct. How steroidmodulated oviduct glycoproteins contribute to the biological function of the fimbria and ampulla oviduct in gamete transport, fertilization and embryo development is currently under intense investigation.

The author is grateful to F. W. Bazer for use of his research flock to obtain tissues for the present study. The excellent assistance of $A$. Brown and E. Nobriega is greatly appreciated and acknowledged. This work was supported by NIH grant HD24998.

\section{References}

Arias EB, Verhage HG and Jaffe RC (1994) Complementary deoxyribonucleic acid cloning and molecular characterization of an oestrogen-dependent human oviductal glycoprotein Biology of Reproduction $51685-694$

Bariether ML and Verhage HG (1981) Control of the secretory cell in cat oviduct by oestradiol and progesterone American Journal of Anatomy 162 107-118

Bazer FW and First NL (1983) Pregnancy and parturition Journal of Animal Science 57 425-460

Boatman DE and Magnoni GE (1995) Identification of sperm penetration factor in the oviduct of the golden hamster Biology of Reproduction 52 199-207

Boatman DE, Felson SE and Kimura J (1994) Changes in morphology, sperm penetration and fertilization of ovulated hamster eggs induced by oviductal exposure Human Reproduction 9 519-526

Boice ML, Geisert RD, Blair RM and Verhage HG (1990) Identification and characterization of bovine oviductal glycoproteins synthesized at oestrus Biology of Reproduction 43 457-465

Brenner RM and Slayden OD (1994) Cyclic changes in the primate oviduct and endometrium. In The Physiology of Reproduction pp 541-569 Eds E Knobil and JO Neill. Raven Press, New York

Buhi WC, Ashworth CJ, Bazer FW and Alvarez IM (1989) In vitro synthesis of oviductal secretory proteins by oestrogen-treated ovariectomized gilts Journal of Experimental Zoology 262 426-435

DeSouza MM and Murray MK (1995) An oestrogen-dependent secretory protein, which shares identity with chitinases, is expressed in a temporal and regional specific manner in the sheep oviduct at the time of fertilization and embryo development Endocrinology 136 2485-2496

Donnelly K, Fazleabas AT, Verhage HG, Mavrogianis PA and Jaffe RC (1991) Cloning of a recombinant complementary DNA to a baboon (Papio anubis) oestradiol-dependent oviduct specific glycoprotein Molecular Endocrinology 5 $356-364$

Eddy CA, Flores JJ, Archer DR and Pauerstein CJ (1978) The role of cilia in fertility: an evaluation by selective microsurgical modification of the rabbit oviduct American Journal of Obstetrics and Gynecology 132 814-821

Eriksen T, Terkelsen O, Hyttel P and Greve T (1994) Ultrastructural features of secretory cells in the bovine oviduct epithelium Anatomical Embryology 190 $583-590$

Ferenczy A and Richart RM (1974) Scanning electron microscopy of human female genital tract New York State Journal of Medicine 74 794-802

Gandolfi F and Moor RM (1987) Stimulation of early embryonic development in the sheep by co-culture with oviduct epithelial cells Journal of Reproduction and Fertility 81 23-29

Gandolfi F, Modina S, Brevini TAL, Galli C, Moor RM and Lauria A (1991) Oviduct ampullary epithelium contributes a glycoprotein to the zona pellucida, perivitelline space and blastomeres membrane of sheep embryos European Journal of Basic and Applied Histochemistry $35383-392$

Henault MA and Killian GJ (1993a) Neutral lipid droplets in bovine oviductal epithelium and lipid composition of epithelial cell homogenates Journal of Dairy Science 76 691-700

Henault MA and Killian GJ (1993b) Composition and morphology of lipid droplets from oviduct epithelial cells Anatomical Record 237 466-474

Hunter RHF (1994) Modulation of gamete and embryonic microenvironments by oviduct glycoproteins Molecular Reproduction and Development 39 $176-181$ 
King RS, Anderson SH and Killian GJ (1994) Effect of bovine oviductal oestrus-associated protein on the ability of sperm to capacitate and fertilize oocytes Journal of Andrology 15 468-478

McComb PF, Halbert SA and Gomel V (1980) Pregnancy, ciliary transport and the reversed ampullary segment of the rabbit fallopian tube Fertility and Sterility 34 386-390

Malette B and Bleau G (1993) Biochemical characterization of hamster oviduct as a sulfated zona pellucida-binding glycoprotein Biochemical Journal 295 $437-445$

Malette B, Paquette $Y$, Merlen $Y$ and Bleau G (1995) Oviductins possess chitinase- and mucin-like domains: a lead in the search for the biological function of these oviduct-specific ZP-associating glycoproteins Molecular Reproduction and Development 41 384-397

Murray MK (1992) Biosynthesis and immunocytochemical localization of an oestrogen-dependent glycoprotein and associated morphological alterations in the sheep ampulla oviduct Biology of Reproduction 47 899-902

Murray MK (1993) An oestrogen-dependent glycoprotein is synthesized and released from the oviduct in a temporal- and region-specific manner during early pregnancy in the ewe Biology of Reproduction 48 446-453

Murray MK (1995) The epithelial lining of the sheep ampulla oviduct undergoes pregnancy-associated morphological changes in secretory status and cell height Biology of Reproduction 53 653-663

Murray MK and DeSouza MM (1995) The messenger RNA encoding an oestrogen-dependent oviduct secretory protein in the sheep is localized in the apical tips and basal compartments of fimbria and ampulla epithelial cells implying translation at unique cytoplasmic foci Molecular Reproduction and Development 42 268-283

Odor DL, Gaddum-Rosse P, Rumery RE and Blandau RJ (1980) Cyclic variations in the oviductal ciliated cells during the menstrual cycle and after oestrogen treatment in the pig-tailed monkey, Macaca nemestrina Anatomical Record $19835-57$
Odor DL, Gaddum-Rosse P, Rumery RE (1983) Secretory cells of the pig-tailed monkey, Macaca nemestrina, during the menstrual cycle and after oestrogen treatment American Journal of Anatomy 166 149-172

Pathak RK, Bajpai VK, Shipstone HC and Karkun JN (1979) The effect of oestrogen on the tubal epithelium of the immature ovariectomized rhesus monkey (Macaca mulatta) Endokrinologie 73 134-144

Sawyer HR, Olson PN and Gorell TA (1984) Effects of progesterone on the oviductal epithelium in oestrogen-primed prepubertal beagles: light and electronmicroscopic observations American Journal of Anatomy 169 75-87

Schmitz G and Muller G (1991) Structure and function of lamellar bodies, lipid-protein complexes involved in storage and secretion of cellular lipids Journal of Lipid Research 32 1539-1570

Sendai $Y$, Abe H, Kikuchi M, Satoh T and Hoshi $H$ (1994) Purification and molecular cloning of bovine oviduct-specific glycoprotein Biology of Reproduction $50 \quad 927-934$

Sendai Y, Komiya H, Suzuki K, Onuma T, Kikuchi M, Hoshi H and Araki Y (1995) Molecular cloning and characterization of a mouse oviduct-specific glycoprotein Biology of Reproduction 53 285-294

Suzuki K, Sendai Y, Onuma T, Hoshi H, Hirol M and Araki Y (1995) Molecular characterization of a hamster oviduct-specific glycoprotein Biology of Reproduction $53 \quad 345-354$

Verhage HG and Fazleabas AT (1988) The in vitro synthesis of oestrogendependent proteins by the baboon (Papio anubis) oviduct Endocrinology $\mathbf{1 2 3}$ $552-558$

Verhage HG, Fazleabas AT and Donnelly K (1988) The in vitro synthesis and release of proteins by the human oviduct Endocrinology 122 1639-1645

Verhage HG, Mavrogianis PA, Boice ML, Li W and Fazleabas AT (1990) Oviduct epithelium of the baboon: hormonal control and the immunogold localization of oviduct-specific glycoproteins American Journal of Anatomy $\mathbf{1 8 7}$ $81-90$ 